\title{
Efeitos do Uso Crônico do Difosfato de Primaquina Sobre a Prenhez da Rata
}

Chronic Effects of Primaquine Diphosphate on Pregnant Rats

Eliel Nina de Azevedo ${ }^{1}$, Alessandra Silva Santos ${ }^{1}$,

Eliane Terezinha Rocha Mendes ${ }^{2}$, Manuel J. Simões ${ }^{3}$, Luiz Kulay Júnior ${ }^{3}$

\begin{abstract}
RESUM0
Objetivo: estudar a ação crônica do difosfato de primaquina sobre a prenhez da rata albina. Métodos: foram utilizadas sessenta ratas prenhes divididas, ao acaso, em seis grupos numericamente iguais. O grupo I recebeu diariamente, por gavagem, $1 \mathrm{ml}$ de água destilada desde o dia zero até o $20^{\circ}$ dia de prenhez (controle). As ratas dos demais grupos também receberam diariamente, por gavagem, durante o mesmo periodo, sempre o volume de $1 \mathrm{ml}$, contendo, solução gradualmente mais concentrada de difosfato de primaquina: $0,25 \mathrm{mg} / \mathrm{kg}$ de peso, grupo II; $0,50 \mathrm{mg} / \mathrm{kg}$ de peso, grupo III; $0,75 \mathrm{mg} / \mathrm{kg}$ de peso, grupo IV; 1,5 mg/kg de peso, grupo V e $3,0 \mathrm{mg} / \mathrm{kg}$ de peso, grupo VI. Os pesos maternos foram considerados no dia zero e no $7^{\circ}, 14^{\circ}$ e $20^{\circ}$ dias de prenhez, quando as matrizes foram sacrificadas.

Resultados: nossos resultados mostraram que o difosfato de primaquina, nas dosagens utilizadas não interferiram em nenhuma das variáveis por nós consideradas, isto é, ganho de peso materno, peso das ninhadas, peso individual médio dos fetos, peso do conjunto das placentas e peso individual médio das placentas, número de implantações, número de placentas e número de fetos, quando comparados com o grupo controle. Não houve, também, nenhum caso de reabsorção, malformações, mortalidade materna ou óbito intra-uterino, em qualquer dos grupos estudados.

Conclusão: nas condições por nós estabelecidas não há contra-indicação para o uso contínuo do difosfato de primaquina durante a prenhez da rata.
\end{abstract}

PALAVRAS-CHAVE: Infecções. Malária. Drogas na gravidez.

\footnotetext{
${ }^{1}$ Departamento de Assistência Materno-Infantil - Universidade Federal do Pará.

2 Departamento de Saúde Materno-Infantil da Faculdade de Medicina da Fundação Universitária do ABC.

${ }^{3}$ Departamento de Tocoginecologia da Universidade Federal de São Paulo/Escola Paulista de Medicina, São Paulo. Correspondência:

Luiz Kulay Júnior

Rua Napoleão de Barros, $715,8^{\circ}$ andar.

Hospital São Paulo, Disciplina de Obstetrícia.

04024-002 - São Paulo - SP
}

Introdução

No exercício diuturno da clínica obstétrica, além da incidência das intercorrências inerentes à especialidade, o profissional se depara com patologias médicas associadas a gravidez. Entre estas, estão as moléstias infecciosas de etiologia diversa, que resultam em graves problemas para a 
saúde pública, exemplo específico a malária, que afeta os três continentes contaminando aproximadamente 500 milhões de pessoas/ano.

No Brasil em 1994, foram noticiados $564 \mathrm{mil}$ $\operatorname{casos}^{16}$. Não conhecemos exatamente o número de grávidas acometidas. Sabemos, porém, que em áreas endêmicas a prevalência da malária e a gravidade do quadro clínico são maiores entre as gestantes do que em mulheres de igual idade nãográvidas ${ }^{13}$; além disso, a incidência é duas vezes maior nas primíparas quando comparada com as multíparas ${ }^{8,9}$.

A malária durante a gravidez modifica a relação do parasita com o hospedeiro. Favorece a instalação de anemia hemolítica que, ao se agravar, pode ocasionar aumento da freqüência de abortamento, prematuridade e retardo de crescimento intra-uterino, como também óbito materno por insuficiência cardíaca congestiva ${ }^{11}$.

Os fármacos utilizados no tratamento da malária durante o ciclo gravídico, isto é, cloroquina, quinina, pirimetamina, mefloquina, sulfadoxina e clindamicina, além de não serem inócuos, não são totalmente eficazes para o tratamento do binômio feto/mãe 4,6,15,18,19,20; aliás, a resistência as drogas é comum, contribuindo para a exacerbação da doença.

Quanto à primaquina, antimalárico derivado da 8-aminoquinolina utilizado desde 1952 , esquizontecida tecidual, responsável pela cura radical das infecções por Plasmodium vivax, Plasmodium ovale e Plasmodium malariae e gametocida para todas as espécies, inclusive o Plasmodium falciparum, não é prescrita durante o período reprodutivo para a espécie humana, em razão de seu potencial e de toxicidade e não ser ainda seu metabolismo bem definido ${ }^{2,3,5,7,17}$.

No campo da experimentação a literatura é escassa. Shen et al. ${ }^{14}$ ministraram dose única de octilamina, 16, 50 e $160 \mathrm{mg} / \mathrm{kg}$ de peso corporal, via intramuscular, somente no sétimo dia de prenhez na rata albina, não tendo observado qualquer efeito deletério sobre as crias e as matrizes no termo da prenhez.

Tal fato nos estimulou a ministrar o difosfato de primaquina durante toda a prenhez da rata para avaliar o efeito do seu uso crônico sobre a rata prenhe e os respectivos conceptos.

\section{Materiais e Métodos}

\section{Animais e tratamento}

Utilizamos ratas (Wistar EPM-1) adultas, virgens, pesando de 150 a $200 \mathrm{~g}$, com regime de alimentação (ração Purina-Labina) e de água à vontade. Foram inicialmente acasaladas na proporção de duas fêmeas para cada macho por um período de duas horas. O teste de prenhez foi determinado pelo encontro de espermatozóides na luz vaginal. Sessenta ratas foram então divididas ao acaso em seis grupos numericamente iguais, a saber: GI, que recebeu água (controle); GII, ao qual foi ministrado $0,25 \mathrm{mg} / \mathrm{kg}$ de peso corporal de difosfato de primaquina (sal gentilmente cedido pala Bayer do Brasil, lote $\mathrm{N}^{\circ}$ 910191, teor de pureza de 99,5\%); GIII, tratado com 0,50 mg/kg de difosfato de primaquina; GIV, que recebeu 0,75 mg/kg de difosfato de primaquina; $\mathrm{GV}$, ao qual foi ministrado $1,5 \mathrm{mg} / \mathrm{kg}$ de difosfato de primaquina, e GVI, tratado com 3,0 mg/kg de difosfato de primaquina. Em todos os grupos o difosfato de primaquina foi sempre dissolvido em $1 \mathrm{ml}$ de água destilada. $\mathrm{O}$ tratamento teve início na data da positividade do teste de prenhez (dia 0) e se estendeu até o $20^{\circ}$ dia; cada rata recebeu diariamente o fármaco por gavagem.

Todas as ratas foram pesadas no dia 0 e no $7^{\circ}, 14^{\circ}$ e $20^{\circ}$ dia de prenhez. O ganho de peso percentual foi calculado de acordo com a seguinte fórmula:

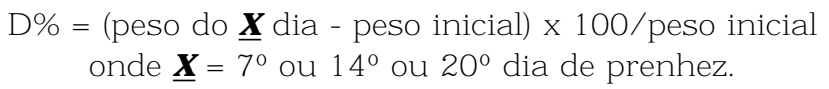

No termo $\left(20^{\circ}\right.$ dia $)$, todos os animais foram sacrificados sob anestesia profunda com éter etílico; após laparotomia seguida de histerotomia, foram anotados os seguintes parâmetros: número de sítios de implantação, número de placentas e de fetos e peso das placentas e dos fetos. Foram procuradas malformações externas.

\section{Análise estatística}

As análises paramétricas e não-paramétricas foram realizadas, o nível de rejeição para hipótese de nulidade foi fixada em 5\%. Múltiplas comparações foram feitas pelo teste de KruskalWallis e análise de variância.

\section{Resultados}

O ganho de peso percentual das ratas pertencentes aos vários grupos tratados com difosfato de primaquina foi semelhante ao dos animais do grupo controle nos períodos estudados, isto é, $0,7,14$ e 21 dias, como pode ser visto na Figura 1.

Quanto ao número de sítios de implantação, número de placentas e de fetos, assim como de seus pesos, encontrados entre os animais expostos 
às várias dosagens de difosfato de primaquina, foram sempre semelhantes aos achados do grupo controle, conforme dados expressos na Tabela 1.

\section{Discussão}

É interessante mencionar inicialmente que o rato é animal sensível às aminoquinolinas, pois doses de $1.000 \mathrm{mg} / \mathrm{kg}$ de peso revelaram-se embriotóxicas e teratogênicas ${ }^{18}$. Considerados os pesos iniciais das ratas dos vários grupos, eles se mostraram homogêneos, não apresentando diferenças significantes no início do experimento. Em todos os seis grupos observamos aumento de peso das matrizes durante toda a prenhez; a curva

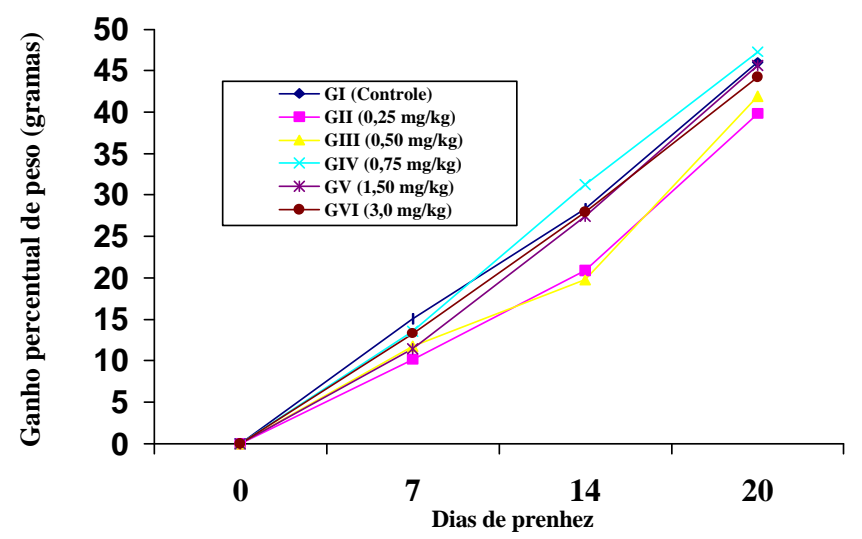

Figura 1 - Ganho de peso $(\mathrm{g})$ das ratas prenhes tratadas com várias dosagens de difosfato de primaquina. Não há diferenças significativas entre as várias curvas. de crescimento sempre foi semelhante ao do grupo controle.

Com relação ao número de implantações também não houve variação quando comparados os grupos tratados entre si e com o grupo controle. É preciso dizer que a dose terapêutica de ataque é $0,75 \mathrm{mg} / \mathrm{kg}$ de peso, ao passo que a de manutenção corresponde a $0,25 \mathrm{mg} / \mathrm{kg}$ de peso, durante 14 dias para a espécie humana ${ }^{3}$. Assim as doses mais elevadas por nós utilizadas, 1,5 e $3,0 \mathrm{mg} / \mathrm{kg}$ de peso, também não apresentaram efeitos deletérios sobre os blastocistos.

No nosso material não foi observado qualquer tipo de malformação entre os grupos por nós estudados. Deve ser mencionado que Moore et al. ${ }^{10}$ relataram dois casos de gestantes que, tratadas profilaticamente com primaquina, tiveram surtos recorrentes de infecção; no entanto, nada foi revelado quanto aos efeitos adversos sobre o concepto. Enquanto a dose máxima por nós ministrada foi de $3,0 \mathrm{mg} / \mathrm{kg}$ de peso durante todo o período embriogênico $\left(5^{\circ}-15^{\circ}\right.$ dia $)$, Shen et al..$^{14}$ injetaram $160 \mathrm{mg} / \mathrm{kg}$ de peso, dose única, no $7^{\circ}$ dia da prenhez. Embora os metabólitos de difosfato de primaquina atuem sobre os ácidos nucléicos interferindo na DNA e RNA polimerase ${ }^{1}$, o teor do fármaco não se revelou embriotóxico nos dois experimentos, visto que não foram observadas dismorfoses nos conceptos.

No que diz respeito ao número de fetos e de placentas e ao pesos das ninhadas e do conjunto de placentas também não houve variação entre os vários grupos tratados entre si e com relação ao grupo controle, ainda que o fármaco em questão tenha sido utilizado durante toda a fase hipertrófica do feto ${ }^{12}$. Assim, parece-nos que deva ser reavaliado o conceito de potencial tóxico ${ }^{3,5,17}$ desta droga uma vez que não foram observados retardo de

Tabela 1 - Efeitos do difosfato de primaquina sobre os vários parâmetros estudados na rata prenhe. Não há diferenças entre os vários grupos estudados.

\begin{tabular}{|c|c|c|c|c|c|c|}
\hline Parâmetro & GI (controle) & $\begin{array}{c}\text { GII (0,25 } \\
\text { mg/kg) }\end{array}$ & $\begin{array}{c}\text { GIII (0,50 } \\
\text { mg/kg) }\end{array}$ & $\begin{array}{c}\text { GIV (0,75 } \\
\text { mg/kg) }\end{array}$ & $\begin{array}{l}\text { GV (1,5 } \\
\text { mg/kg) }\end{array}$ & $\begin{array}{c}\text { GVI }(3,0 \\
\text { mg/kg) }\end{array}$ \\
\hline Número de fetos & $9,80 \pm 2,22$ & $9,60 \pm 0,00$ & $9,30 \pm 4,44$ & $9,60 \pm 1,25$ & $9,50 \pm 1,25$ & $9,90 \pm 1,56$ \\
\hline $\begin{array}{l}\text { Peso individual médio } \\
\text { dos fetos }(\mathrm{g})\end{array}$ & $3,43 \pm 1,06$ & $3,54 \pm 1,04$ & $3,42 \pm 1,12$ & $3,41 \pm 1,10$ & $3,35 \pm 1,09$ & $3,39 \pm 1,11$ \\
\hline Número de placentas & $9,80 \pm 1,91$ & $9,60 \pm 1,54$ & $9,30 \pm 1,35$ & $9,60 \pm 1,60$ & $9,50 \pm 1,70$ & $9,90 \pm 1,57$ \\
\hline $\begin{array}{l}\text { Peso individual médio } \\
\text { das placentas }(\mathrm{g})\end{array}$ & $0,47 \pm 0,01$ & $0,45 \pm 0,02$ & $0,48 \pm 0,01$ & $0,46 \pm 0,02$ & $0,53 \pm 0,01$ & $0,49 \pm 0,03$ \\
\hline Número de implantações & $9,80 \pm 0,01$ & $9,60 \pm 0,02$ & $9,30 \pm 0,01$ & $9,60 \pm 0,02$ & $9,50 \pm 0,01$ & $9,90 \pm 0,03$ \\
\hline
\end{tabular}

$G=$ grupo 
crescimento e/ou óbito intra-uterino.

Enfim, nas condições por nós estabelecidas, dosagens progressivas de difosfato de primaquina $(0,25 ; 0,5 ; 0,75 ; 1,5$ e $3,0 \mathrm{mg} / \mathrm{kg}$ de peso corporal por dia) durante toda a prenhez da rata albina não revelaram qualquer efeito adverso sobre a matriz e suas crias.

\section{SUMMARY}

Purpose: to evaluate the chronic action of primaquine diphosphate on the pregnancy of female albino rats.

Methods: sixty pregnant female rats, separated into six groups, were used. Group I received daily, by gavage, $1 \mathrm{ml}$ of distilled water from day zero to the 20th day of pregnancy (control group). The female rats of the other groups also received daily, by gavage, during the same period of time the volume of $1 \mathrm{ml}$ containing gradually concentrated primaquine diphosphate solution: $0.25 \mathrm{mg} / \mathrm{kg}$, group II; $0.50 \mathrm{mg} / \mathrm{kg}$, group III; 0.75 $\mathrm{mg} / \mathrm{kg}$, group $\mathrm{IV} ; 1.5 \mathrm{mg} / \mathrm{kg}$, group $V$ and $3.0 \mathrm{mg} / \mathrm{kg}$, group VI. The maternal weights were considered on day zero and on the 7th, 14th and 20th days of pregnancy, when the matrices were sacrificed.

Results: the results showed that primaquine diphosphate, in the used doses, did not interfere with none of the following variables: maternal weight, newborn weight, medium individual weight offetuses, weight of the group of placentas and medium individual weight of the placentas, implantation number, number of placentas and number of fetuses, when compared with the control group. Also there was no case of reabsorption, malformation, maternal mortality or intrauterine death, in any of the studied groups.

Conclusion: in the conditions of the study there were no contraindications for the continuous use of primaquine diphosphate during the pregnancy of the female rat.

KEY WORDS: Infections. Malaria. Drugs in pregnancy.

\section{Referências}

1. Aikawa M. Variations in structure in function during the life cycle of malarial parasites. Bull World Health Org 1977; 55: 139-56.

2. Bia FJ. Malaria prophylaxis: taking aim at constantly moving targets. Yale J Biol Med 1992; 65: 32936.

3. Burattini MN. Malária. In: Prado FC, Ramos JA, Valle JR, editores. Atualização terapeutica: manual prático de diagnóstico e tratamento. 18 ed. São Paulo: Artes Médicas; 1997. p. 69-72.
4. Covell G. Congenital malaria. Trop Dis Bull 1950; 47:1147-67.

5. Diro M, Beydoun SN. Malaria in pregnancy. South Med J 1982; 75: 959-62.

6. Heinonen OP, Slone D, Shapiro S. Birth defects and drugs in pregnancy. MA: Littleton, 1977.

7. Idowu OR, Peggins JO, Brewer TG. Side-chain hydroxylation in the metabolism of 8 aminoquinoline antiparasitic agents. Drug Metab Dispos 1995; 23: 18-27.

8. McGregor IA, Wilson ME, Billewicz WZ. Malaria infection of the placenta in Gambia, West Africa: its incidence and relationship to stillbirth, birthweight and placental weight. Trans $\mathbf{R}$ Soc Trop Med Hyg 1983; 77: 232-44.

9. McGregor IA. Epidemiology, malaria and pregnancy. Am J Trop Med Hyg 1984; 33: 517-25.

10.Moore TA, Tomayko Jr JF, Wierman AM, Rensimer ER, White Jr AC. Imported malaria in the 1990s. A report of 59 cases from Houston, Tex. Arch Fam Med 1994; 3: 130-6.

11.Nathwani D, Currie PF, Douglas JG, Green ST, Smith NC. Plasmodium falciparum malaria in pregnancy: a review. Br J Obstet Gynaecol 1992: 99: 118-21.

12.Porto AGM, Hauschild D. Crescimento intra-uterino retardado. In: Piato S, Tedesco JJA. Diagnóstico e terapêutica das patologias obstétricas. São Paulo: Atheneu; 1984. p.223-33.

13.Reinhardt MC, Gautier R, Reinhardt NM. A study of 204 consecutive deliveries in Abidjan - Anthropometric data of newborns, mothers and placentas. Helv Paediatr Acta Suppl 1978: 21-42.

14.Shen PL, Xu JM, Qian XM, Zhang YP, Yu YC, Ye JF. The embryotoxicity of primaquine octylamide in rats. Chi Sheng Chung Hsueh Yu Chi Shen Chung Ping Tsa Chih 1985; 3: 201-2.

15.Shepard TH. Catalog of teratogenic agents. $6^{\text {th }}$ ed. Baltimore: Johns Hopkins University Press; 1989. p. $538-41$.

16.Silva AR. Resistência do Plasmodium falciparum na Amazônia oriental. Skopia 1995; 17-19.

17.Trenholme GM, Carson PE. Therapy and prophylaxis of malaria. JAMA 1978; 240: 2293-5.

18. Udalova LD. The effect of chloroquine on the embryonal development of rats. Pharmacol Toxicol 1967; 2: 226-8.

19.Weiss WR, Oloo AJ, Johnson A, Koech D, Hoffman SL. Daily primaquine is effective for prophylaxis against falciparum malaria in Kenya: comparison with mefloquine, doxycycline, and chloroquine plus proguanil. J Infect Dis 1995; 171: 1569-75.

20.World Health Organization. Practical chemotherapy of malaria. World Health Organ Tech Rep Ser. 1990:1-141. 